\title{
Blends de frutos tropicais à base de tamarindo
}

\section{Blends with tropical fruits based on tamarind}

\author{
Maria Rejane de Abrantes Gadelha ${ }^{1}$, Jaqueline de Sousa Gomes ${ }^{2}$, Amanda Kelly da Silva ${ }^{3}$, Maria Jaízia \\ dos Santos Alves ${ }^{4}$, Adriana Ferreira dos Santos ${ }^{5}$
}

${ }^{1}$ Mestre em Sistemas Agroindustriais, Universidade Federal de Campina Grande, Pombal, (83) 99978-3958, rejaneabrantes30@ gmail.com; ${ }^{2}$ Mestranda em Sistemas Agroindustriais, Universidade Federal de Campina Grande, Pombal, jaquelinesousa_pb@hotmail.com; ${ }^{3}$ Engenheira de Alimentos, Universidade Federal de Campina Grande, Pombal, amanda_dkelly@hotmail.com; ${ }^{4}$ Doutoranda em Engenharia de Alimentos, Universidade Federal de Santa Catarina, Florianópolis, jaizia2011@gmail.com; ${ }^{5}$ Professora do Centro de Ciências e Tecnologia Agroalimentar, Universidade Federal de Campina Grande, Pombal; adrefesantos@ccta.ufcg.edu.br.

\section{A R T I G O}

Recebido: $10 / 12 / 2018$

Aprovado: 14/06/2019
Key words:

Processing

Mixed juice

Mixed drink

\section{R E S U M O}

Um dos recursos à disposição da indústria para a produção de bebidas com novos sabores, coloração atraente, textura e valor nutricional é o desenvolvimento de suco ou néctar de frutos. O objetivo do trabalho foi avaliar a qualidade de polpas e néctares e a partir dessa avaliação, desenvolver blends de frutos tropicais quantificando-os em relação aos aspectos físico-químicos e compostos bioativos presentes. A partir das polpas dos frutos do tamarindo, abacaxi, acerola e maracujá, foram elaborados néctares com $30 \%$ de polpa e $70 \%$ de água mineral, utilizados como matrizes para a elaboração de sete formulações de blends. As polpas, néctares e blends foram submetidos a análises físico-químicas (sólidos solúveis, acidez, pH e ratio) e de compostos bioativos (ácido ascórbico, clorofila, carotenoides, antocianinas, flavonoides e polifenóis extraíveis totais). $\mathrm{O} \mathrm{pH}$ das polpas, néctares e todas as formulações apresentaram valores abaixo de 4,5. A polpa e o néctar de acerola apresentaram o maior teor de ácido ascórbico, clorofila, antocianinas e polifenóis extraíveis totais. A Formulação 7 (30\% tamarindo $+20 \%$ abacaxi $+25 \%$ acerola $+25 \%$ maracujá) apresentou o maior teor de acidez titulável, ácido ascórbico, antocianinas, flavonoides e carotenoides. A Formulação 4 (30\% tamarindo $+30 \%$ abacaxi $+30 \%$ acerola $+10 \%$ maracujá) foi a que apresentou o maior teor de polifenóis extraíveis totais.

\section{A B S T R A C T}

The research of fruit juice and nectars provides drinks with new flavors, attractive colors and textures, and high nutritional value for the beverage industries. This study aimed to evaluate the quality of pulps and nectars, develop blends of tropical fruits, and assess their physicochemical features and presence of bioactive compounds. The preparation of nectars comprised $30 \%$ pulp and $70 \%$ mineral water, using pulps of tamarind, pineapple, acerola, and passion fruit, which served as matrices for the preparation of seven blend formulations. The following physicochemical characteristics and bioactive compounds were analyzed: soluble solids (SS), titratable acidity (TA), pH, SS/TA ratio, ascorbic acid, chlorophyll, carotenoids, anthocyanins, flavonoids, and total extractable polyphenols. All pulps, nectars, and blends had a pH below 4.5. The acerola pulp and nectar presented the highest ascorbic acid, chlorophyll, anthocyanin, and extractable polyphenol contents. The blend in Formulation 7 (30\% tamarind $+20 \%$ pineapple $+25 \%$ acerola $+25 \%$ passion fruit) had the highest titratable acidity, ascorbic acid, anthocyanins, flavonoids, and carotenoids. Formulation 4 (30\% tamarind $+30 \%$ pineapple $+30 \%$ acerola $+10 \%$ passion fruit) showed the highest content of total extractable polyphenols.

\section{INTRODUÇÃO}

Os frutos são produtos perecíveis, o que implica em perdas pós-colheita maior que $30 \%$. O processamento dos frutos para obtenção de polpas, sucos e néctares constituem uma forma de reduzi-las e agregar maior valor econômico (SOUSA et al., 2010).

Os sucos de frutas são consumidos e apreciados em todo mundo, não só pelo seu sabor, mas também por serem fontes naturais de nutrientes (CARDOSO et al., 2015). Dentre os frutos tropicais, podemos destacar: tamarindo, abacaxi,

\section{Revista Verde}

ISSN 1981-8203

Pombal, Paraíba, Brasil v. 14, n.3, jul.-set, p.412-419, 2019 doi: $10.18378 /$ rvads.v14i3.6215 
acerola e maracujá. O tamarindo apresenta significativo nível de vitaminas $\mathrm{C}, \mathrm{E}$ e do complexo $\mathrm{B}$, além de cálcio, ferro, fósforo, potássio, manganês e fibra dietética. Há também compostos orgânicos que o tornam um poderoso antioxidante e um agente anti-inflamatório (URSZULA et al., 2014). O abacaxi possui baixo valor energético, proveniente praticamente todo de açúcares e contribui para a ingestão de sais minerais (cálcio, fósforo, magnésio, potássio, sódio, cobre e iodo) e vitaminas, principalmente ácido ascórbico, tiamina e riboflavina (TACO, 2011). Combinado com outros frutos resulta num produto com melhor qualidade nutricional e funcional.

A acerola é um fruto de elevada acidez, baixo valor de $\mathrm{pH}$ e baixo teor de açúcares. Com essas características, geralmente é consumida misturada com outras frutas devido a sua limitação quanto ao apelo sensorial. O teor elevado de vitamina C constitui seu principal valor nutricional (VENTURINI FILHO et al., 2010). Os frutos do maracujáamarelo são ricos em compostos fenólicos (Talcott et al., 2003), carotenoides (Souza et al., 2004), minerais, vitaminas (Lima, 2002), como por exemplo, vitamina C, cálcio e fósforo (FERRARI et al., 2004).

O processamento desses frutos tropicais em forma de blends é uma alternativa de minimizar os excedentes na época de safra e agregar valor aos frutos da região, em particular o tamarindo, pouco explorado no Brasil e com características nutricionais relevantes, oferecendo ao mercado competitivo, novos produtos, com melhores propriedades do fruto in natura e maior aproveitamento de suas propriedades funcionais. Desta forma, o objetivo do trabalho foi avaliar a qualidade de polpas e néctares e a partir dessa avaliação, desenvolver blends de frutos tropicais quantificando-os em relação aos aspectos físico-químicos e compostos bioativos presentes.

\section{MATERIAL E MÉTODOS}

O trabalho foi desenvolvido no Centro de Ciências e Tecnologia Agroalimentar, Unidade Acadêmica de Tecnologia de Alimentos, da Universidade Federal de Campina Grande, em Pombal, Paraíba, no Laboratório de Tecnologia de Produtos de Origem Vegetal (LTPOV), localizado na Microrregião do Sertão Paraibano. Os frutos de tamarindo, abacaxi, acerola e maracujá, foram selecionados com o mesmo grau de maturação e adquiridos em um único lote, no mercado varejista de Sousa-PB.

Para obtenção das polpas, os frutos foram recebidos no Setor de Fruticultura do Campus do Instituto Federal de Ensino Tecnológico, localizado no Perímetro Irrigado de São Gonçalo, Sousa - PB, selecionados quanto aos seus atributos de qualidade (cor, grau de maturação, isenção de doenças etc.) e lavados por imersão em água clorada (50ppm) por 15 minutos. Em seguida, foram desintegrados e despolpados. As polpas obtidas foram armazenadas em sacos plásticos de $500 \mathrm{~g}$, fechadas hermeticamente, rotuladas e armazenadas a temperatura de congelamento, até as mesmas serem submetidas às avaliações físico-químicas e de compostos bioativos.

Após a realização das análises das polpas in natura, foram processados os néctares. As polpas foram submetidas a uma proporção de $30 \%$ de polpa e $70 \%$ de água mineral, com padronização do teor de sólidos solúveis para $15^{\circ}$ Brix. Os néctares foram então formulados, armazenados em garrafas de PET de $1000 \mathrm{~mL}$ e fechados de imediato por tampas plásticas rosqueáveis, para posteriores análises e submissão como matriz para a mistura dos blends (Tabela 1).

Tabela 1. Tratamentos dos blends formulados a partir dos néctares dos frutos de tamarindo, abacaxi, acerola e maracujá.

\begin{tabular}{|c|c|}
\hline Tratamentos & Néctar \\
\hline $\mathrm{F} 1$ & $\begin{array}{c}30 \% \text { (tamarindo), } 30 \% \text { (abacaxi), } 20 \% \\
\text { (acerola) }+20 \% \text { (maracujá) }\end{array}$ \\
\hline $\mathrm{F} 2$ & $\begin{array}{c}30 \% \text { (tamarindo), } 30 \% \text { (abacaxi), } 25 \% \\
\text { (acerola) }+15 \% \text { (maracujá) }\end{array}$ \\
\hline F3 & $\begin{array}{c}30 \% \text { (tamarindo), } 30 \% \text { (abacaxi), } 15 \% \\
\text { (acerola) }+25 \% \text { (maracujá) }\end{array}$ \\
\hline $\mathrm{F} 4$ & $\begin{array}{c}30 \% \text { (tamarindo), } 30 \% \text { (abacaxi), } 30 \% \\
\text { (acerola) }+10 \% \text { (maracujá) }\end{array}$ \\
\hline F5 & $\begin{array}{c}30 \% \text { (tamarindo), } 25 \% \text { (abacaxi), } 25 \% \\
\text { (acerola) }+20 \% \text { (maracujá) }\end{array}$ \\
\hline F6 & $\begin{array}{c}30 \% \text { (tamarindo), } 25 \% \text { (abacaxi), } 20 \% \\
\text { (acerola) }+25 \% \text { (maracujá) }\end{array}$ \\
\hline F7 & $\begin{array}{c}30 \% \text { (tamarindo), } 20 \% \text { (abacaxi), } 25 \% \\
\text { (acerola) }+25 \% \text { (maracujá) }\end{array}$ \\
\hline
\end{tabular}

A partir da obtenção dos néctares foram desenvolvidas as sete formulações de blends, com base em préexperimentos. Os néctares dos frutos tropicais foram utilizados como matrizes, onde o néctar de tamarindo representou $30 \%$ das formulações e os $70 \%$ foram quantificados com os néctares de abacaxi, acerola e maracujá. Os blends foram enriquecidos com os néctares dos frutos tropicais de acordo com os tratamentos (Tabela 1), em seguida, as bebidas formuladas foram submetidas a tratamento térmico à temperatura de $90^{\circ} \mathrm{C}$ por 1 minuto, envasadas a quente em garrafas de polietileno de $200 \mathrm{ml}$, fechadas com tampas plásticas com lacre, invertidas, resfriadas por imersão em água clorada (100 ppm) e submetidas a avaliações físico-químicas e de compostos ativos.

\section{Avaliações físico-químicas}

Sólidos Solúveis (\%): determinados com refratômetro digital (KRÜSS-OPTRONIC, HAMBURGO, ALEMANHA), segundo AOAC (2005).

Acidez Titulável (g/100g de ácido cítrico): por titulometria com $\mathrm{NaOH} 0,1 \mathrm{~mol} / \mathrm{L}$, segundo Instituto Adolfo Lutz (2008) e expressa em ácido cítrico.

pH: determinado com potenciômetro digital (HANNA, SINGAPURA), conforme técnica da Association of Official Analytical Chemists - AOAC (2005).

Ratio: foi obtida dividindo-se os valores de sólidos solúveis pelos valores da acidez titulável.

\section{Determinação dos compostos bioativos}

Ácido Ascórbico $\left(\mathrm{mg} .100^{-1} \mathrm{~g}\right)$ : quantificado utilizando-se método de titulometria com solução de DFI (2,6 diclorofenolindofenol a $0,2 \%$, até coloração rósea clara permanente, segundo AOAC (2005).

Carotenoides Totais $\left(\mu \mathrm{g} . \mathrm{g}^{-1}\right)$ e clorofila $\left(\mathrm{mg} .100 \mathrm{~g}^{-1}\right)$ : determinados com cerca de $1 \mathrm{~g}$ de amostra para polpa e $1 \mathrm{ml}$ para néctar e blend, macerada com 0,2 g de carbonato de cálcio $\left(\mathrm{CaCO}_{3}\right)$ e $5 \mathrm{~mL}$ de acetona $(80 \%)$ gelada, em ambiente escuro. Em seguida, as amostras foram centrifugadas a $10^{\circ} \mathrm{C}$ e $3.000 \mathrm{rpm}$ por 10 minutos e os sobrenadantes foram lidos em espectrofotômetro nos 
comprimentos de onda de 470, 646 e 663nm, de acordo com Lichtenthaler (1987).

Flavonoides e antocianinas (mg.100g $\left.{ }^{-1}\right)$ : determinados com cerca de $1 \mathrm{~g}$ de amostra para polpa e $1 \mathrm{ml}$ para néctar e blend, macerada com $10 \mathrm{~mL}$ de solução extratora de etanol $95 \%$ mais $\mathrm{HCl}$ 1,5 N na proporção 85:15 (v/v). Em seguida, transferidas para tubos (envoltos com papel alumínio) e deixados em repouso por 24 horas sob refrigeração. As amostras foram filtradas em papel de filtro e as leituras foram realizadas em espectrofotômetro a $374 \mathrm{~nm}$ para os flavonoides e $535 \mathrm{~nm}$ para as antocianinas, as determinações seguiram a metodologia de Francis (1982).

Polifenóis extraíveis totais (mg.GAE. $100 \mathrm{~g}^{-1}$ ): determinados pesando aproximadamente $1 \mathrm{~g}$ de amostra para polpa e $1 \mathrm{ml}$ para néctar e blend, diluídas em água e acrescidas de $0,125 \mathrm{~mL}$ do reagente Folin-Ciocalteau, seguido de agitação e repouso por 5 minutos. Foram utilizadas alíquotas distintas para as polpas, néctares e blends. Logo após o tempo de reação, foram adicionados $0,250 \mathrm{~mL}$ de carbonato de sódio $20 \%$, seguida de nova agitação e repouso em banho-maria a $40^{\circ} \mathrm{C}$ por 30 minutos. A curva padrão foi preparada com ácido gálico e as leituras foram realizadas em espectrofotômetro a $765 \mathrm{~nm}$, estimados de acordo com o método de Folin-Ciocalteau descrito por Waterhouse (2006).

\section{Análise estatística}

Para as análises físico-químicas e compostos bioativos das polpas e néctares foram utilizadas as médias gerais e o seu desvio padrão. E para as análises dos blends os experimentos foram instalados em um delineamento inteiramente casualizado e os resultados submetidos à análise de variância. Quando detectado significância para o teste F, os dados foram comparados pelo teste de Tukey ao nível de 5\% de probabilidade. Para as avaliações das polpas, néctares e das formulações dos blends nas sete formulações foram utilizadas com 4 (quatro) repetições. A análise estatística foi realizada pelo Programa Assistat (SILVA, 2010).

\section{RESULTADOS E DISCUSSÃO}

De acordo com os resultados apresentados na Tabela 2, observa-se que os teores de sólidos solúveis (SS) para as polpas variaram de 4,03\% (polpa de acerola) a 16,03\% (polpa de tamarindo), com melhores resultados para as polpas de tamarindo e abacaxi. Segundo a legislação o valor mínimo de SS para a polpa de acerola é de 5,5\% e $11 \%$ para maracujá, ou seja, as polpas em estudo estão abaixo deste limite, provavelmente estes baixos teores devem-se aos fatores ambientais de produção. As polpas de tamarindo e abacaxi encontram-se dentro dos valores mínimos estabelecidos pela legislação (6\% e 11\%, respectivamente) (BRASIL, 2000). Canuto et al., (2010), encontrou na polpa da acerola um índice de SS de 3,5\%. Os teores de SS na polpa de maracujá encontrados neste trabalho foram de $10,78 \%$, demonstrando que a amostra estudada se encontra abaixo do limite mínimo de $11 \%$ estipulado pela legislação (BRASIL, 2000).

Tabela 2. Teores de sólidos solúveis, acidez titulável, $\mathrm{pH}$, ratio e ácido ascórbico em polpas de frutas tropicais

\begin{tabular}{ccccc}
\hline Polpas & Tamarindo & Abacaxi & Acerola & Maracujá \\
Características & & $12,88 \pm 0,13$ & $4,03 \pm 0,10$ & $10,78 \pm 0,17$ \\
Sólidos solúveis(\%) & $16,03 \pm 0,10$ & $4,15 \pm 0,12$ & $3,83 \pm 0,11$ & $3,32 \pm 0,16$ \\
pH & $2,99 \pm 0,06$ & $0,60 \pm 0,05$ & $0,93 \pm 0,05$ & $2,91 \pm 0,15$ \\
Acidez titulável $\left(\mathrm{g} .100 \mathrm{~g}^{-1}\right)$ & $4,39 \pm 0,04$ & $21,45 \pm 0,33$ & $4,33 \pm 0,23$ & $3,71 \pm 0,15$ \\
Rátio & $3,66 \pm 0,50$ & $20,79 \pm 0,93$ & $315,29 \pm 23,25$ & $20,99 \pm 0,21$ \\
Ácido ascórbico $\left(\mathrm{mg}^{1} 100 \mathrm{~g}^{-1}\right)$ & $16,01 \pm 0,02$ & & & \\
\hline
\end{tabular}

*Médias seguidas de desvio padrão.

As médias de pH das polpas variaram de 2,99 (polpa de tamarindo) a 4,15 (polpa de abacaxi), classificando-as como ácidas (Tabela 2). A polpa de tamarindo foi a que apresentou $\mathrm{pH}$ mais reduzido de $(2,99)$, superior ao encontrado por Canuto et al., (2010), que relataram 2,5 de pH. Os valores baixos de $\mathrm{pH}$ são preferidos para indústria, constituindo-se um fator favorável ao baixo favorecimento das atividades enzimáticas e desenvolvimento de microrganismos. O resultado obtido para a polpa de abacaxi foi semelhante ao encontrado por Santos et al., (2016) estudando a caracterização físico-química de polpas de abacaxi congeladas ( $\mathrm{pH} 3,50$ a 4,23). Na polpa de maracujá, o pH médio foi de 3,32, estando em concordância com os de Raimundo et al., (2009) encontrado para polpa de maracujá congelada (pH 2,67 a 3,77).

Um dos critérios utilizados para a classificação de frutos quanto ao sabor, odor, estabilidade e qualidade são a determinação de acidez titulável (AT). A variação entre as polpas foi de 0,60 g. $100 \mathrm{~g}^{-1}$ (polpa de abacaxi) a 4,39 g. $100 \mathrm{~g}^{-1}$ (polpa de tamarindo), com valores menores para as polpas de abacaxi e acerola. O conteúdo de AT encontrado no tamarindo foi menor que o valor relatado por Canuto et al., 2010, que observou $30,6 \mathrm{mg}$. $100 \mathrm{~g}^{-1}$. A polpa de abacaxi apresentou uma média de $0,60 \mathrm{~g} .100 \mathrm{~g}^{-1}$ para a acidez, estando em conformidade com a legislação vigente, tendo valor mínimo estipulado de $0,30 \mathrm{~g} \cdot 100 \mathrm{~g}^{-1}$ de ácido cítrico. A acidez titulável da polpa de maracujá $\left(2,91 \mathrm{~g} \cdot 100 \mathrm{~g}^{-1}\right)$ apresentou valor superior ao mínimo exigido pela legislação (BRASIL, 2000), que é de $2,5 \mathrm{~g} .100 \mathrm{~g}^{-1} \mathrm{e}$ inferior aos mencionados na literatura por Hurtado-Salazar et al., (2015) para polpa de maracujá congelada $\left(4,43 \mathrm{~g} \cdot 100 \mathrm{~g}^{-1}\right.$ a $\left.5,11 \mathrm{~g} \cdot 100 \mathrm{~g}^{-1}\right)$.

$\mathrm{O}$ ratio indica a relação existente entre o teor de açúcares e ácidos orgânicos, referente ao sabor dos produtos, o valor dessa relação pode ser visto na Tabela 2. O maior valor apresentado para o ratio foi para polpa de abacaxi $(21,45)$ e o menor para polpa de tamarindo $(3,66)$. Os baixos teores do ratio nas polpas avaliadas indicam uma baixa palatabilidade, devido à alta acidez do próprio fruto (Tabela 2).

Entre as polpas avaliadas, o teor de ácido ascórbico variou de $16,01 \mathrm{mg} .100 \mathrm{~g}^{-1}$ (tamarindo) a $315 \mathrm{mg} \cdot 100 \mathrm{~g}^{-1}$ (acerola). Canuto et al., (2010), encontraram 0,1 mg.100 $\mathrm{g}^{-1} \mathrm{de}$ ácido ascórbico para caracterização de polpa de tamarindo, valor inferior ao apresentado neste estudo. O ácido ascórbico tem função muito importante devido a sua ação fortemente redutora e é largamente empregado como agente antioxidante para estabilizar a cor e ao aroma do alimento. Honorato et al., (2015) estudando polpa congelada de abacaxi, encontrou o 
valor médio de 15,66 mg. $100 \mathrm{~g}^{-1}$ de ácido ascórbico, valor abaixo do encontrado no presente trabalho para esta fruta, que foi de $20,79 \mathrm{mg}$ de ácido ascórbico. $100 \mathrm{~g}^{-1}$. O resultado encontrado para a polpa de acerola no estádio maduro encontra-se de acordo com os resultados detectados por Araújo et al., (2017), que caracterizando polpa de acerola comercial encontraram teores de ácido ascórbico variando de 610,0 a $111,0\left(\mathrm{mg} .100 \mathrm{~g}^{-1}\right)$ de polpa. A polpa de maracujá apresentou valor médio de $20,99 \mathrm{mg} \cdot 100 \mathrm{~g}^{-1} \mathrm{de}$ ácido ascórbico, sendo inferior ao encontrado por Hurtado-Salazar et al., (2015) que estudaram o teor de ácido ascórbico na polpa de diferentes espécies de maracujá, sendo o valor médio encontrado de 29,37 a $36,06 \mathrm{mg} \cdot 100 \mathrm{~g}^{-1}$.
De acordo com a Tabela 3, observamos os valores médios dos teores de clorofila, carotenoides, flavonoides, antocianinas e polifenóis extraíveis totais das polpas de frutas utilizadas como matéria-prima para obtenção dos néctares. Foram constatados baixos teores de clorofila para as polpas avaliadas, para as polpas de tamarindo, acerola e maracujá foi de $0,61 \mathrm{mg} .100 \mathrm{~g}^{-1}, \quad 0,79 \mathrm{mg} .100 \mathrm{~g}^{-1}, \quad 0,40 \mathrm{mg}^{1} 100 \mathrm{~g}^{-1}$, respectivamente, já para a polpa de abacaxi apenas traços de clorofila foram encontrados. Uma das possíveis causas deste baixo teor de clorofila nas polpas pode está relacionado ao estádio de maturação do fruto.

Tabela 3. Teor de clorofilas totais $\left(\mathrm{mg} .100 \mathrm{~g}^{-1}\right)$, carotenoides totais $\left(\mu \mathrm{g} .100 \mathrm{~g}^{-1}\right)$, flavonoides $\left(\mathrm{mg} .100 \mathrm{~g}^{1}\right)$, antocianinas $\left(\mathrm{mg} .100 \mathrm{~g}^{1}\right)$ e polifenóis extraíveis totais $\left(\mathrm{mg} .100 \mathrm{~g}^{-1}\right)$ em polpas de frutos tropicais.

\begin{tabular}{|c|c|c|c|c|}
\hline $\begin{array}{c}\text { Polpas } \\
\text { Características }\end{array}$ & Tamarindo & Abacaxi & Acerola & Maracujá \\
\hline Clorofilas Totais $\left(\mathrm{mg} .100 \mathrm{~g}^{-1}\right)$ & $0,61 \pm 0,11$ & - & $0,79 \pm 0,33$ & $0,40 \pm 0,03$ \\
\hline Carotenoides Totais $\left(\mu \mathrm{g} .100 \mathrm{~g}^{-1}\right)$ & $5,59 \pm 4,08$ & $0,30 \pm 0,03$ & $4,25 \pm 0,07$ & $2,98 \pm 0,65$ \\
\hline Flavonoides (mg.100g $\left.{ }^{-1}\right)$ & $4,85 \pm 2,01$ & $0,38 \pm 0,09$ & $3,44 \pm 0,51$ & $2,21 \pm 0,59$ \\
\hline Antocianinas $\left(\mathrm{mg}^{1} 100 \mathrm{~g}^{-1}\right)$ & $0,72 \pm 0,32$ & $1,55 \pm 2,93$ & $4,95 \pm 1,05$ & $0,17 \pm 0,06$ \\
\hline Polifenóis extraíveis totais $\left(\mathrm{mg} 100 \mathrm{~g}^{-1}\right)$ & $20,35 \pm 1,23$ & $26,40 \pm 0,61$ & $544,35 \pm 43,22$ & $20,14 \pm 0,46$ \\
\hline
\end{tabular}

*Médias seguidas de desvio padrão.

Os conteúdos de carotenoides totais (Tabela 3) variaram de $0,30 \mu \mathrm{g} .100 \mathrm{~g}^{-1}$ (polpa de abacaxi) a $5,59 \mu \mathrm{g} .100 \mathrm{~g}^{-1}$ (polpa de tamarindo). Os teores de flavonoides (Tabela 3) variaram de $0,38 \mathrm{mg} \cdot 100 \mathrm{~g}^{-1}$ (polpa de abacaxi) a $4,85 \mathrm{mg} \cdot 100 \mathrm{~g}^{-1}$ (polpa de tamarindo). A polpa de acerola superior a 1,04 $\mu \mathrm{g} .100 \mathrm{~g}^{-1} \mathrm{e}$ maracujá inferior a $0,90 \mu \mathrm{g} .100 \mathrm{~g}^{-1}$, ambas encontrado por Sousa et al., (2011).

As quantidades de antocianinas apresentadas na Tabela 3 , variaram entre $0,17 \mathrm{mg} .100 \mathrm{~g}^{-1}$ (polpa de maracujá) a 4,95 mg. $100 \mathrm{~g}^{-1}$ (polpa de acerola). Os baixos valores indicam que elas sofreram degradação, ocasionada pela temperatura, luz ou por enzimas, já que são pigmentos muito instáveis. Sousa et al., 2011 avaliando compostos antioxidantes em resíduos de polpas de frutas tropicais não detectaram antocianinas na polpa de abacaxi.
De acordo com os resultados observados na Tabela 3, verificou-se que os teores de compostos fenólicos variaram de $20,14 \mathrm{mg} \cdot 100 \mathrm{~g}^{-1}$ (polpa de maracujá) a $544,35 \mathrm{mg} \cdot 100^{-1} \mathrm{~g}$ (polpa de acerola). A quantidade de polifenóis extraíveis totais em frutos é variável e depende, entre muitos fatores, do estádio de maturação e das condições de armazenamento (Veberic et al., 2008), podendo influenciar no sabor, nas características tecnológicas, como escurecimento ou precipitação durante o processamento, assim como no potencial nutricional e funcional das frutas (ROCHA et al., 2011).

Para os néctares, o valor médio de $\mathrm{pH}$ variou de 2,87 para o néctar de tamarindo a 4,10 para o néctar de abacaxi (Tabela 4). A legislação brasileira não estabelece um valor mínimo de $\mathrm{pH}$ como padrão de identidade e qualidade para o néctar de maracujá.

Tabela 4. Sólidos solúveis, acidez titulável, $\mathrm{pH}$, ratio e ácido ascórbico em néctares de frutas tropicais.

\begin{tabular}{ccccc}
\hline Néctares & Abacaxi & Acerola & Maracujá \\
Características & & & & $3,59 \pm 0,07$ \\
pH & $2,87 \pm 0,04$ & $4,10 \pm 0,06$ & $3,75 \pm 0,06$ & $0,70 \pm 0,01$ \\
Acidez titulável $\left(\mathrm{g} .100 \mathrm{~g}^{-1}\right)$ & $1,60 \pm 0,04$ & $0,20 \pm 0,00$ & $0,43 \pm 0,00$ & $3,26 \pm 0,06$ \\
Rátio & $13,72 \pm 1,78$ & $26,11 \pm 1,72$ & $6,99 \pm 0,10$ & $8,80 \pm 0,22$ \\
Ácidoascórbico $\left(\mathrm{mg} .100 \mathrm{~g}^{-1}\right)$ & $4,68 \pm 0,26$ & $11,25 \pm 0,22$ & $47,44 \pm 1,12$ & \\
\hline
\end{tabular}
*Médias seguidas de desvio padrão.

O teor de acidez titulável (AT) variou entre 0,2 g. $100 \mathrm{~g}^{-1}$ (néctar de abacaxi) a $1,6 \mathrm{~g} \cdot 100 \mathrm{~g}^{-1}$ de ácido cítrico (néctar de tamarindo) (Tabela 4). Os resultados encontrados nesse estudo estão de acordo com os padrões de identidade e qualidade para néctar de acerola (BRASIL, 2003), que estabelece o valor de acidez total de no mínimo $0,20 \mathrm{~g} .100 \mathrm{~g}$ ${ }^{1}$ de ácido cítrico. O valor encontrado para o néctar de abacaxi está de acordo com a legislação vigente (BRASIL, 2003), que estabelece valor mínimo de $0,12 \mathrm{~g} .100 \mathrm{~g}^{-1}$. Miranda et al., (2015) estudando a elaboração e caracterização de néctar de abacaxi pérola adoçado com glucose de milho, encontrou valor médio de $0,23 \mathrm{~g} .100 \mathrm{~g}^{-1}$, apresentando semelhanças para os valores de acidez encontrado neste trabalho.

$\mathrm{O}$ ratio variou de 3,26 (néctar de maracujá) a 26,11 (néctar de abacaxi) (Tabela 4). O néctar de abacaxi apresentou valor superior ao encontrado por Borges et al. (2011) que foi de 17,19 e por Pinheiro et al., (2006) que detectaram valores de 12,7 a 17,6. Pinheiro et al., (2006) avaliando sucos concentrados de maracujá obtiveram um valor mínimo de 3,1 e máximo de 4,4 para a o ratio, valores estes próximos ao encontrado nessa pesquisa para o mesmo néctar $(3,26)$. 
Com relação ao conteúdo de ácido ascórbico, podemos observar na Tabela 4 que houve uma variação de 4,68 (néctar de tamarindo) a 47,44 mg.100g ${ }^{-1}$ (néctar de acerola). Os valores encontrados para o néctar de acerola foram mais expressivos, quando comparados aos demais néctares, porém abaixo do valor mínimo exigido pela legislação que é de 160 mg. $100 g^{-1}$ (BRASIL,2003).

De acordo com os resultados observados na Tabela 5, o teor de clorofila total para os néctares variou entre 0,03 (Maracujá) a 0,66 mg.100g ${ }^{-1}$ (Acerola). O teor de carotenoides variou de 0,07 (néctar de abacaxi) a $1,82 \mu \mathrm{g} .100 \mathrm{~g}^{-1}$ (néctar de tamarindo). Maia; Sousa; Lima (2007) em estudo realizado com suco de acerola envasado pelo processo hot fill encontrou valores de carotenoides totais de $0,59 \mu \mathrm{g} .100 \mathrm{~g}^{-1}$, inferior ao encontrado neste trabalho. $\mathrm{O}$ teor de flavonoides variou de $0,35 \mathrm{mg} \cdot 100 \mathrm{~g}^{-1}$ (néctar de abacaxi) a $1,11 \mathrm{mg} \cdot 100 \mathrm{~g}^{-1}$ (néctar de tamarindo).
Foram detectados baixos teores de antocianinas para os néctares de todos os frutos tropicais como pode ser observado na Tabela 5. Para suco de acerola avaliado por Freitas et al., (2006) observou-se valores médios de 0,41 mg.100 $\mathrm{g}^{-1} \mathrm{de}$ antocianinas, sendo superior ao encontrado no presente estudo. As antocianinas são pigmentos muito instáveis, podendo facilmente sofrer degradação, o que pode justificar as variações observadas entre os dados obtidos no estudo atual e os dados referenciais apresentados. Para os sucos de maracujá analisados por Fernandes et al., (2011) foi encontrado 0,26 a $0,29 \mathrm{mg} \cdot 100 \mathrm{~g}^{-1}$ de antocianinas, também superior ao encontrado no presente estudo. $\mathrm{O}$ teor de compostos fenólicos variou de $0,7 \mathrm{mg} \cdot 100 \mathrm{~g}^{-1}$ (néctar de abacaxi) a $14,67 \mathrm{mg} .100 \mathrm{~g}^{-1}$ (néctar de acerola), com melhores resultados para os néctares de tamarindo e acerola.

Tabela 5. Teor de clorofila totais, carotenoides totais, flavonoides, antocianinas e polifenóis extraíveis totaisem néctares de frutas tropicais.

\begin{tabular}{|c|c|c|c|c|}
\hline $\begin{array}{c}\text { Néctares } \\
\text { Características }\end{array}$ & Tamarindo & Abacaxi & Acerola & Maracujá \\
\hline Clorofilas Totais (mg.100g ${ }^{-1}$ ) & $0,08 \pm 0,02$ & $0,06 \pm 0,09$ & $0,66 \pm 0,07$ & $0,03 \pm 0,02$ \\
\hline Carotenoides totais $\left(\mu \mathrm{g} .100 \mathrm{~g}^{-1}\right)$ & $1,64 \pm 0,29$ & $0,07 \pm 0,06$ & $1,82 \pm 0,23$ & $1,53 \pm 0,18$ \\
\hline Flavonoides $\left(\mathrm{mg} .100 \mathrm{~g}^{-1}\right)$ & $1,11 \pm 0,30$ & $0,35 \pm 0,05$ & $0,73 \pm 0,14$ & $0,49 \pm 0,10$ \\
\hline Antocianinas (mg.100g $\left.{ }^{-1}\right)$ & $0,14 \pm 0,05$ & $0,06 \pm 0,02$ & $0,35 \pm 0,14$ & $0,03 \pm 0,01$ \\
\hline Polifenóis extraíveis totais $\left(\mathrm{mg} .100 \mathrm{~g}^{-1}\right)$ & $14,62 \pm 0,31$ & $0,70 \pm 0,01$ & $14,67 \pm 1,20$ & $11,46 \pm 0,63$ \\
\hline
\end{tabular}

*Médias seguidas de desvio padrão.

Na Tabela 6, pode-se observar que os teores de sólidos solúveis apresentaram pequenas variações entre as sete formulações dos blends, com a formulação 4 apresentando um pequeno aumento em comparação as demais. Esta pequena oscilação deve-se a padronização destes durante o processamento e formulação dos néctares para $15^{\circ}$ Brix.

Para os resultados de acidez titulável apresentados na Tabela 6, verificou-se também pouca oscilação entre as formulações dos blends. Observando que os valores variaram de 0,71 g. $100 \mathrm{~g}^{-1}$ (F1) para 1,06 g.100 $\mathrm{g}^{-1}$ (F7). Esses valores encontrados estão acima dos resultados encontrados por Pereira et al., (2009) em estudo avaliando o desenvolvimento de bebida mista à base de água de coco com polpa de abacaxi e acerola, onde obteve valores de acidez titulável variando de
0,24 g. $100 \mathrm{~g}^{-1}$ a 0,52 g. $100 \mathrm{~g}^{-1}$ devido aos elevados valores de acidez da polpa e do néctar do tamarindo. Canuto et al., (2010), caracterizando polpa de tamarindo verificou elevados teores de ácidos orgânicos $\left(30,6\right.$ g. $\left.100 \mathrm{~g}^{-1}\right)$, contribuindo para valores de acidez elevada, desta forma como o tamarindo foi base de todas as formulações pode-se justificar os valores detectados no presente estudo.

$\mathrm{O}$ pH para as sete formulações de blends variou de 3,46 (F2) a 3,74 (F5), apresentando pequena oscilação. Os valores encontrados estão abaixo de 4,5, valor que delimita o desenvolvimento de microrganismos e praticamente não variaram entre as formulações com a mesma concentração de suco de tamarindo, que proporcionou menores valores de $\mathrm{pH}$, atribuindo-se à acidez elevada deste suco (Tabela 6).

Tabela 6. Sólidos solúveis, acidez titulável, $\mathrm{pH}$, rátio e ácido ascórbico em sete formulações de blends com néctares dos frutos de tamarindo, abacaxi, acerola e maracujá

\begin{tabular}{|c|c|c|c|c|c|}
\hline Formulações & $\begin{array}{c}\text { Sólidos } \\
\text { Solúveis }(\%)\end{array}$ & $\begin{array}{c}\text { Acidez } \\
\text { Titulável } \\
\left({\left.\mathrm{g} .100 \mathrm{~g}^{-1}\right)}\right.\end{array}$ & $\mathrm{pH}$ & Ratio & $\begin{array}{l}\text { Ácido Ascórbico } \\
\left(\mathrm{mg} \cdot 100 \mathrm{~g}^{-1)}\right.\end{array}$ \\
\hline F1 & $15,03 a \pm 0,10$ & $0,71 \mathrm{a} \pm 0,03$ & $3,60 \mathrm{a} \pm 0,25$ & $21,17 \mathrm{a} \pm 0,1$ & $70,38 \mathrm{~d} \pm 0,54$ \\
\hline $\mathrm{F} 2$ & $14,40 b \pm 0,29$ & $0,78 \mathrm{a} \pm 0,02$ & $3,46 a \pm 0,21$ & $18,46 b \pm 0,23$ & $98,23 b c \pm 4,64$ \\
\hline F3 & $14,95 \mathrm{a} \pm 0,17$ & $0,76 a \pm 0,11$ & $3,64 a \pm 0,26$ & $19,67 b \pm 1,03$ & $59,78 d \pm 4,63$ \\
\hline F4 & $15,20 \mathrm{a} \pm 0,18$ & $0,70 \mathrm{a} \pm 0,03$ & $3,62 \mathrm{a} \pm 0,17$ & $21,71 \mathrm{c} \pm 0,35$ & $105,84 b \pm 9,53$ \\
\hline F5 & $14,95 \mathrm{a} \pm 0,30$ & $0,75 a \pm 0,06$ & $3,74 a \pm 0,22$ & $19,93 b \pm 0,25$ & $87,90 \mathrm{c} \pm 4,10$ \\
\hline F6 & $14,23 b \pm 0,21$ & $0,81 \mathrm{a} \pm 0,07$ & $3,62 \mathrm{a} \pm 0,07$ & $17,57 b \pm 0,42$ & $69,43 d \pm 5,33$ \\
\hline F7 & $14,15 b \pm 0,13$ & $1,06 a \pm 0,22$ & $3,61 \mathrm{a} \pm 0,15$ & $13,35 \mathrm{c} \pm 0,09$ & $121,87 \mathrm{a} \pm 10,96$ \\
\hline
\end{tabular}

*Médias seguidas de desvio padrão. **Médias seguidas por letras iguais, na mesma coluna, não diferem significativamente entre ao nível de 95\% de confiança $(\mathrm{P} \leq 0,05)$. *** F1: 30\% (tamarindo), 30\% (abacaxi), 20\% (acerola) + 20\% (maracujá); F2: 30\% (tamarindo), 30\% (abacaxi), 25\% (acerola) + 15\% (maracujá); F3: 30\% (tamarindo), 30\% (abacaxi), 15\% (acerola) + 25\% (maracujá); F4: 30\% (tamarindo), 30\% (abacaxi), 30\% (acerola) + 10\% (maracujá); F5: 30\% (tamarindo), 25\% (abacaxi), 25\% (acerola) + 20\% (maracujá); F6: 30\% (tamarindo), 25\% (abacaxi), 20\% (acerola) + 25\% (maracujá); F7: $30 \%$ (tamarindo), $20 \%$ (abacaxi), 25\% (acerola) $+25 \%$ (maracujá). 
A relação do ratio para as sete formulações dos blends oscilou de 21,71 (F4) a 13,35 (F7). O ratio, de acordo com Chitarra; Chitarra (2005) indica o grau de doçura de um fruto ou de seu produto, evidenciando qual o sabor predominante, o doce ou o ácido, ou ainda se há equilíbrio entre eles. Essa relação é uma das formas mais utilizadas para a avaliação do sabor, sendo mais representativo que a medição isolada de açúcares ou da acidez. O ratio é uma forma de avaliar a receptividade do consumidor decorrente do sabor, consistindo num melhor indicador de sabor do que os conteúdos de açucares e de acidez, medidos isoladamente. Para o mercado consumidor, quanto maior a relação do ratio mais desejável se torna o produto (MANICA et al., 2001).

De acordo com os resultados, os teores de ácido ascórbico variam de 59,7 (F3) a 121,7 (F7) mg.100g ${ }^{-1}$. A vitamina $\mathrm{C}$ presente em sucos de frutas pode oxidar rapidamente quando expostas ao ar, calor, luz e pH alcalino (ARAÚJO,2011). Matsuura; Rolim (2002) encontraram teores de ácido ascórbico de $20,9 \mathrm{mg} \cdot 100 \mathrm{~g}^{-1}$ para suco integral pasteurizado de abacaxi, sendo que, a utilização de misturas de frutas ricas em vitamina $C$ na elaboração de blends vem sendo testadas, uma vez que, tende a aumentar o teor de vitamina $\mathrm{C}$.
De acordo com a Tabela 7 , os teores de clorofila nas formulações variaram de $0,05 \mathrm{mg} \cdot 100^{-1} \mathrm{~g}$ (F2) a $1,79 \mathrm{mg} \cdot 100^{-}$ ${ }^{1} \mathrm{~g}$ (F1), não havendo diferença significativa. O conteúdo de carotenoides também apresentou poucas variações entre as formulações com valores muito baixos.

$\mathrm{Na}$ Tabela 7, encontram-se o teor de flavonoides amarelos, que variaram de 0,62 (F3) a 0,83 (F7), com pouca diferença entre as formulações. Os valores obtidos para o teor de antocianinas totais apresentaram diferença significativa $(\mathrm{p} \leq 0,05)$, variando de 0,57 (F7) a $0,26 \mathrm{mg} .100 \mathrm{~g}^{-1}$ (F3). As antocianinas são pigmentos solúveis em água, amplamente difundidas no reino vegetal e conferem as várias nuances de cor entre laranja, vermelha e azul encontradas em frutas, vegetais, flores, folhas e raízes. A interação de antocianinas com ácido ascórbico em presença de oxigênio causa a degradação de ambos os compostos, com descoloração dos pigmentos, o que também ocorre em presença de aminoácidos, fenóis e derivados de açúcar. Portanto, a degradação das antocianinas e do ácido ascórbico ocorre simultaneamente em sucos de frutas, durante o processamento e a estocagem de alimentos. As antocianinas presentes nos blends podem ter sido significativamente degradadas pelo processamento térmico.

Tabela 7. Teor de clorofilas totais, carotenoides totais, flavonoides, antocianinas e polifenóis extraíveis totaisem sete formulações de blends com néctares dos frutos de tamarindo, abacaxi, acerola e maracujá

\begin{tabular}{|c|c|c|c|c|c|}
\hline Características & $\begin{array}{l}\text { Clorofilas totais } \\
\quad\left(\mathrm{mg} .100 \mathrm{~g}^{-1}\right)\end{array}$ & $\begin{array}{l}\text { Carotenoides } \\
\text { Totais } \\
\left(\mu \mathrm{g} .100 \mathrm{~g}^{-1}\right) \\
\end{array}$ & $\begin{array}{l}\text { Flavonoides } \\
\qquad\left(\mathrm{mg} / 100 \mathrm{~g}^{-1}\right)\end{array}$ & $\begin{array}{r}\text { Antocianinas } \\
\left(\mathrm{mg} / 100 \mathrm{~g}^{-1}\right)\end{array}$ & $\begin{array}{c}\text { Polifenóis } \\
\text { Extraíveistotais } \\
\left(\mathrm{mg} / 100 \mathrm{~g}^{-1}\right) \\
\end{array}$ \\
\hline $\mathrm{F} 1$ & $1,79 a \pm 3,42$ & $1,18 \mathrm{~b} \pm 0,13$ & $0,75 \mathrm{a} \pm 0,10$ & $0,35 \mathrm{~d} \pm 0,07$ & $49,58 \mathrm{a} \pm 1,21$ \\
\hline $\mathrm{F} 2$ & $0,05 a \pm 0,03$ & $1,13 b \pm 0,15$ & $0,73 a \pm 0,14$ & $0,43 c \pm 0,08$ & $38,37 b \pm 2,11$ \\
\hline F3 & $0,04 a \pm 0,03$ & $1,13 b \pm 0,16$ & $0,62 \mathrm{a} \pm 0,26$ & $0,26 \mathrm{~d} \pm 0,10$ & $39,35 b \pm 1,21$ \\
\hline $\mathrm{F} 4$ & $0,07 a \pm 0,08$ & $1,18 b \pm 0,13$ & $0,76 a \pm 0,13$ & $0,50 b \pm 0,09$ & $51,57 \mathrm{a} \pm 2,76$ \\
\hline F5 & $0,04 a \pm 0,05$ & $1,03 b \pm 0,09$ & $0,72 \mathrm{a} \pm 0,17$ & $0,48 \mathrm{~d} \pm 0,11$ & $34,43 b \pm 0,81$ \\
\hline F6 & $0,03 a \pm 0,04$ & $1,21 b \pm 0,16$ & $0,71 \mathrm{a} \pm 0,08$ & $0,42 \mathrm{c} \pm 0,05$ & $36,46 b \pm 2,27$ \\
\hline F7 & $0,05 a \pm 0,02$ & $1,54 \mathrm{a} \pm 0,09$ & $0,83 a \pm 0,13$ & $0,57 \mathrm{a} \pm 0,08$ & $35,05 \mathrm{~b} \pm 2,41$ \\
\hline
\end{tabular}

*Médias seguidas de desvio padrão. **Médias seguidas por letras iguais, na mesma coluna, não diferem significativamente entre ao nível de $95 \%$ de confiança $(\mathrm{P} \leq 0,05)$. *** F1: 30\% (tamarindo), 30\% (abacaxi), 20\% (acerola) + 20\% (maracujá); F2: 30\% (tamarindo), 30\% (abacaxi), 25\% (acerola) + 15\% (maracujá); F3: 30\% (tamarindo), 30\% (abacaxi), 15\% (acerola) + 25\% (maracujá); F4: 30\% (tamarindo), 30\% (abacaxi), 30\% (acerola) + 10\% (maracujá); F5: 30\% (tamarindo), 25\% (abacaxi), 25\% (acerola) + 20\% (maracujá); F6: 30\% (tamarindo), 25\% (abacaxi), 20\% (acerola) + 25\% (maracujá); F7: 30\% (tamarindo), $20 \%$ (abacaxi), $25 \%$ (acerola) $+25 \%$ (maracujá)

Como pode ser observado na Tabela 7, os teores de polifenóis extraíveis totais diferiram significativamente $(p \leq$ $0,05)$ entre as formulações, apresentando uma variação de 51,57 (F4) a 34,43 mg.100 g ${ }^{-1}$ (F5). Os compostos fenólicos são responsáveis pela atividade antioxidante de diversos vegetais, dentre os compostos com propriedade antioxidante, destacam-se os flavonoides que, quimicamente englobam as antocianinas e os flavonoides.

\section{CONCLUSÕES}

As polpas de tamarindo, abacaxi, acerola e maracujá utilizadas para desenvolvimento dos néctares e blends tem aspectos físico-químicos e bioativos ( $\mathrm{pH}$, ácido ascórbico, carotenoides, flavonoides e polifenóis extraíveis totais) que contribuem para as características nutricionais e funcionais das bebidas.

O uso dos frutos tropicais, em particular o tamarindo, pouco empregado em processamentos, permite a obtenção um produto inovador, com excelentes características nutricionais e funcionais, sendo o blend uma alternativa viável para utilização de frutos perecíveis, sazonais, que não tem um aproveitamento total na forma in natura, agregando maior valor econômico ao produto.

\section{REFERÊNCIAS}

ARAUJO, J. M. A. Química de alimentos. Viçosa- MG: Editora UFV, 2011. 601p.

ARAÚJO, M. N. T.; CASTRO, R. S.; RODRIGUES, A. C. S.; RÊGO, J. F.; UCHÔA, V. T. Avaliação do teor de vitamina $\mathrm{C}$ em polpas de acerola comercializadas em supermercados de Piripiri-PI. Ciência Agrícola, v.15, n.1, p.59-68, 2017. 10.28998/rca.v15i1.2609

AOAC (ASSOCIATION OF OFFICIAL ANALITICAL CHEMISTRS). Official methods of analysis of the association of official analytical chemistrs. 18 ed. Gathersburg, 2005. 1015p. 
BORGES. P. R.; CARVALHO, E. E. N.; VILA BOAS, E. V. B.; LIMA, J. P.; RODRIGUES, L. F. Estudo da estabilidade físico-química de suco de abacaxi 'pérola'. Ciência e Agrotecnologia, v.35, n.4, p.742-750, 2011. 10.1590/S141370542011000400013 .

BRASIL. Ministério da Agricultura, Pecuária e Abastecimento. Instrução normativa $\mathrm{n}^{\circ} 12$, de 4 de setembro de 2003. Estabelece o regulamento técnico para fixação dos padrões de identidade e qualidade gerais para o suco tropical e dá outras providências. Diário Oficial da República Federativa do Brasil, Brasília, n.174, p. 1-25, 2003.

BRASIL. Ministério da Agricultura, Pecuária e Abastecimento. Instrução normativa $\mathrm{n}^{\circ} 01$, de 7 de janeiro de 2000. Estabelece o regulamento técnico geral para fixação dos padrões de identidade e qualidade para polpa de fruta. Diário Oficial da República Federativa do Brasil, Brasília, 7 de jan. de 2000 .

CANUTO, G. A. B.; XAVIER, A. A. O.; NEVES, L. C.; BENASSI, M. T. Caracterização físico-química de polpas de frutos da Amazônia e sua correlação com a atividade antiradical livre. Revista Brasileira de Fruticultura, v.32, n.4, p.1196-1205, 2010. 10.1590/S0100-29452010005000122.

CARDOSO, J. A. C.; ROSSALES, R. R. LIMONS, B.; REIS, S. F.; SCHUMACHER, B. O.; HELBIG, E. Teor e estabilidade de vitamina $\mathrm{C}$ em sucos in natura $\mathrm{e}$ industrializados. Revis. o Mundo da Saúde, v. 39, n. 4, p. 460 - 469, 2015. 10.15343/0104-7809.20153904460469.

CHITARRA, M. I. F.; CHITARRA, A. B. Pós-colheita de frutas e hortaliças: fisiologia e manuseio. 2.ed. Lavras: UFLA, 2005. 785p

FERNANDES, A. G.; SANTOS, G. M.; SILVA, D. S.; SOUSA, P. H. M.; MAIA, G. A.; FIGUEREIDO, R. W. Alterações das características químicas e físico-químicas durante as etapas de processamento do suco de maracujá. Ciência e Tecnologia de Alimentos, vol.31, n.3, p.747-751, 2011. 10.1590/S0101-20612011000300030.

FERRARI, R. S.; COLUSSI, F.; AYUB, R. A. Caracterização de subprodutos da industrialização do maracujá aproveitamento das sementes. Revista Brasileira de Fruticultura, v.26, n.1, p.101-102, 2004. 10.1590/S010029452004000100027.

FRANCIS, F. J. Analysis of anthocyanins. In: MARKAKIS, P. (ed). Anthocyanins as food colors.New York: Academic Press, 1982. p.280.

FREITAS, C. A. S.; MAIA, G. A.; DA COSTA, J. M. C.; FIGUEIREDO, R. W.; SOUSA, P. H. M.; FERNANDES, A. G. Estabilidade dos carotenoides, antocianinas, vitamina C presentes no suco tropical de acerola (Malpighiaemarginata D.C.) adoçado envasado pelos processos hot fill e asséptico. Ciência e Agrotecnologia, v.30, n.5, p.942-949, 2006. $\underline{10.1590 / \mathrm{S} 1413-70542006000500018 .}$.

HONORATO, A. C.; DIAS, C. B. R.; SOUZA, E. B.; CARVALHO, I. R. B.; SOUSA, K. S. M. Parâmetros físico- químicos de polpas de fruta produzidas na cidade de Petrolina - PE. Revista Verde, v. 10, n.4, p.01-05, 2015. 10.18378/rvads.v10i4.3415.

HURTADO-SALAZAR, A.; SILVA, D. F. P.; SEDIYAMA, C. S.; BRUCKNER, C. H. Caracterização física e química de frutos de maracujazeiro-amarelo enxertado em espécies silvestres do gênero passiflora cultivado em ambiente protegido. Revista Brasileira de Fruticultura, v.37, n.3, p. 635-643, 2015. 10.1590/0100-2945-101/14.

INSTITUTO ADOLFO LUTZ. Normas analíticas do Instituto Adolfo Lutz: métodos químicos e físicos para análise de alimentos. 4.ed. São Paulo: Instituto Adolfo Lutz, 2008.

LICHTENTHALER, H. K. Chlorophylls and carotenoids: pigments of photosynthetic biomembranes. In: PACKER, L.; DOUCE, R. (Eds). Methods in Enzimology, v.148, p.350382, 1987.

LIMA, A. A. Maracujá produção: aspectos técnicos. Brasília: EMBRAPA, 2002. 104p.

MAIA, G. A.; SOUSA, P. H. M.; LIMA, A. S. Processamento de sucos de frutas tropicais. 1.ed. Fortaleza: UFC, 2007. 320p.

MANICA, I.; ICUMA, I. M.; JUNQUEIRA, N. T. V.; SALVADOR, J. O.; MOREIRA, A.; MALAVOLTA, E. Goiaba: do plantio ao consumidor. Porto Alegre: Cinco Continentes, 2001. 32p.

MATSUURA, F. C. A. U.; ROLIM, R. B. Avaliação da adição de suco de acerola em suco de abacaxi visando à produção de um blend com alto teor de vitamina C. Revista Brasileira de Fruticultura, v.24, n.1, p.138-141, 2002. 10.1590/S0100-29452002000100030.

MIRANDA, D. S. A.; PESSOA, T.; FIGUÊREDO, R. M. F.; GURJÃO, F. F.; PINHEIRO, R. M. M.; MARTINS, A. G. L. A. Elaboração e caracterização de néctar de abacaxi pérola adoçado com glucose de milho. Revista AGROTEC. v.36, n.1, p.82-87, 2015. 10.25066/agrotec.v36i1.23092

PEREIRA, M. A. B.; SIEBENEICHLER, S. C.; LORENÇONI, R.; ADORIAN, G. C.; SILVA, J. C.; GARCIA, R. B. M.; PEQUENO, D. N. L.; SOUZA, C. M.; BRITO, R. F. F. Qualidade do fruto de abacaxi comercializado pela Cooperfruto - Miranorte - TO. Revista Brasileira de Fruticultura, v.31, n.4, p.1048-1053, 2009. 10.1590/S0100-29452009000400018.

PINHEIRO, A. M.; FERNANDES, A. G.; FAI, A. E. C.; PRAD, G. M.; SOUSA, P. H. M.; MAIA, G. A. Avaliação química, físico-química e microbiológica de sucos de frutas integrais: abacaxi, caju e maracujá. In: Ciência e Tecnologia de Alimentos, v.26 n.1, p.98-103,2006. 10.1590/S010120612006000100017

RAIMUNDO, K.; MAGRI, R. S.; SIMIONATO, E. M. R. S.; SAMPAIO, A. C. Avaliação física e química da polpa de maracujá congelada comercializada na região de Bauru. 
Revista Brasileira de Fruticultura, v. 31, n.2, p.539-543, 2009. 10.1590/S0100-29452009000200031.

ROCHA, W. S.; LOPES, R. M.; SILVA, D. B.; VIEIRA, R. F.; SILVA, J. P.; AGOSTINI-COSTA, T. S. Compostos fenólicos totais e taninos condensados em frutas nativas do cerrado. Revista Brasileira de Fruticultura, v.33, n.4. p.12151221, 2011. 10.1590/S0100-29452011000400021.

SANTOS, E. H. F.; NETO, A. F. DONZELI, V. P. Aspectos físico-químicos e microbiológicos de polpas de frutas comercializadas em Petrolina (PE) e Juazeiro (BA). Brazilian Journal of Food Technology, v.19, 2016. 10.1590/19816723.8915

SILVA, F. A. S.; AZEVEDO, C. A. V. The Assistat Software Version 7.7 and its use in the analysis of experimental data. African Journal of Agricultural Research, v.11, n.39, p.37333740, 2010. 10.5897/AJAR2016.11522.

SOUSA, M. S. B.; VIEIRA, L. M.; SILVA, M. J. M.; LIMA, A. Caracterização nutricional e compostos antioxidantes em resíduos de polpas de frutas tropicais. Ciência e Agrotecnologia, v.35, n.3, p.554-559, 2011. 10.1590/S1413$\underline{70542011000300017}$.

SOUSA, P. H. M.; RAMOS, A. M.; MAIA, G. A.; BRITO, E. S.; GARRUTI, D. S.; FONSECA, A. V. V. Adição de extratos de Ginkgobiloba e Panaxginseng em néctares mistos de frutas tropicais. Ciência e Tecnologia de Alimentos, v.30, n.2, p.463-470, 2010. 10.1590/S0101-20612010000200025.

SOUZA, S. L.; MOREIRA, A. P. B.; SANTANA, H. M. P.; ALENCAR, E. R. Conteúdo de carotenos e provitamina A em frutas comercializadas em Viçosa, Estado de Minas Gerais. Acta Scientiarum Agronomy, v.26, n.4, p.453-459, 2004. 10.4025/actasciagron.v26i4.1807.

TACO - Tabela Brasileira de Composição de Alimentos. 4.ed. Campinas: UNICAMP-NEPA, 2011. 161p.

TALCOTT, S. T.; PERCIVAL, S. S.; PITTET-MOORE, J.; CELORIA, C. Phytochemical Composition and Antioxidant Stability of Fortified Yellow Passion Fruit (Passifloraedulis).Journal of Agricultural and Food Chemistry, v.51, n.4, p.935-941, 2003. 10.1021/jf020769q.

URSZULA, T.; LÓPEZ, J.F.; ÁLVAREZ, J.A.P.; MARTOS, M.V. Chemical, physicochemical, technological, antibacterial and antioxidant properties of rich-fibre powder extract obtained from tamarind (Tamarindusindica L.). Industrial Crops and Products, v.55, p.155-162, 2014. 10.1016/j.indcrop.2014.01.047.

VEBERIC, R .; COLARIC, M ; STAMPAR, F. Phenolic acids and flavonoids of fig fruit (Ficuscarica L.) in the northern Mediterranean region. FoodChemistry, v.106, n.1, p.153-157, 2008. 10.1016/j.foodchem.2007.05.061.

VENTURINI FILHO, W.G. Bebidas não alcoólicas. 2.ed. São Paulo: Bluncher, 2010. 385p.
WATERHOUSE, A. Folin-ciocalteau micro method for total phenol in wine. American Journal of Enology and Viticulture, p. 3-5, 2006. 